\title{
A CROSS-SECTIONAL DESCRIPTIVE STUDY OF NUTRITIONAL STATUS AND DISTRIBUTION OF COMMON ILLNESSES AMONG SCHOOL GOING CHILDREN OF AGE 5 - 10 YEARS IN A RURAL PRIMARY SCHOOL IN TRICHY DISTRICT, TAMILNADU
}

\author{
D. Saminathan ${ }^{1}$, D. Prabakar'2, K. Shiyamala ${ }^{3}$
}

1 Professor and HOD, Department of Paediatrics, Chennai Medical College Hospital \& Research Centre, Irungalur, Trichy, Tamilnadu. ${ }^{2}$ Assistant Professor, Department of Paediatrics, Madras Medical College, Institute of Child Health, Egmore, Chennai, Tamilnadu. 3 Junior Resident, Department of Paediatrics, Chennai Medical College Hospital \& Research Centre, Irungalur, Trichy, Tamilnadu.

\section{ABSTRACT}

\section{BACKGROUND}

Malnutrition is a major cause of morbidity and mortality among children of $3^{\text {rd }}$ world countries including India. This study is undertaken to find out the present status of undernutrition among a particular rural school in Irungalur village in the age group of 5-10 years, and the comorbid conditions which are present in these children. Undernutrition, early marriage, anaemia and illnesses, low birth weight babies in the mother greatly contribute to malnutrition and poor scholastic performance among children especially in the 5-10 years age group where the growth potential and cognitive development is very high.

\section{MATERIAL AND METHODS}

A cross-sectional descriptive study was undertaken in the month of February 2017 among 134 School children between ages of 5 10 years belonging to rural village area of Chennai Medical College Hospital \& Research Centre, Irungalur situated $30 \mathrm{~km}$ outskirts of Trichy district. Agricultural labour was the main occupation among the parents of these children. Trichy being delta region rice cultivation is the main occupation in this area and the rural poor people, both men and women are engaged in agricultural labour and belong to low socioeconomic status. This village constitutes mostly these agricultural labourers and their children study in this government aided primary school.

\section{RESULTS}

All 134 children between 5 - 10 years studying in Government aided primary school, Irungalur between $1^{\text {st }} \& 5^{\text {th }}$ Standard were taken up for study, out of which 83 were male and 51 were female. Their height and weight were measured. Height was measured using stadiometer and weight was measured using electronic weighing machine. Each child was screened for routine, general and systemic examination starting from head to toe and for any illnesses. On analysing their weight, grading the children according to IAP classification for weight for age, 37.30\% were $>80 \%$ of the expected weight, $40.29 \%$ were grade I, $20.14 \%$ were grade II, $4.47 \%$ were grade III. According to Waterlow classification for height for age, $75.37 \%$ were above $95 \%$ of expected height, $18.65 \%$ were grade I, $5.22 \%$ were grade II, $0.74 \%$ were grade III. On disease morbidity, the commonest illness was URI with $23.79 \%$ and the other common illnesses were anaemia (22.38\%) and dental caries (13.43\%). Other illnesses were learning disability with $2.9 \%$ and Impetigo with $2.23 \%$.

\section{CONCLUSION}

It is therefore concluded that $64.9 \%$ were malnourished whereas the national average of malnutrition is $42.5 \% .{ }^{1}$ Analysing their height, $24.61 \%$ were below $95^{\text {th }}$ percentile of expected height for age whereas the national average is $48.3 \%$. Similarly, the most common illness found in children was URI with $23.79 \%$ and the other common illnesses were Anaemia (22.38\%) and dental caries $(13.43 \%)$.

\section{KEYWORDS}

Malnutrition, Weight, Height, Anaemia, School Going Children, Morbidity.

HOW TO CITE THIS ARTICLE: Saminathan D, Prabakar D, Shiyamala K. A cross-sectional descriptive study of nutritional status and distribution of common illnesses among school going children of age 5 - 10 years in a rural primary school in Trichy district, Tamilnadu. J. Evolution Med. Dent. Sci. 2017;6(54):4072-4075, DOI: 10.14260/Jemds/2017/880

\section{BACKGROUND}

Malnutrition is a major cause of morbidity and mortality among children in India especially in rural

Financial or Other, Competing Interest: None.

Submission 18-05-2017, Peer Review 22-06-2017,

Acceptance 29-06-2017, Published 06-07-2017.

Corresponding Author:

Dr. D. Saminathan,

Professor and $H O D$

Department of Paediatrics,

Chennai Medical College Hospital \& Research Centre,

Irungalur, Trichy-621105,

Tamilnadu, India.

E-mail: dsaminathan842@gmail.com

DOI: $10.14260 /$ jemds $/ 2017 / 880$

(c) $($ ) $\$$
India.(1-4) Even though Tamilnadu is the state with good health indicators, still malnutrition is a predisposing factor for common illness like URI, anaemia, diarrhoea and otitis media. So as to assess the real prevalence of malnutrition among rural school children of poor socioeconomic status hailing from agriculture background, this study was undertaken in a Government aided primary school with 134 children between the ages of 5-10 years, both boys and girls studying between $1^{\text {st }}$ and $5^{\text {th }}$ standard, where midday meal scheme is provided to all children providing 300 extra kilocalories.

Malnutrition is a major cause of morbidity and mortality among children of $3^{\text {rd }}$ world countries including India. In India, national figures for undernutrition is $42.5 \%$. In 
Tamilnadu the incidence of undernutrition is $29.8 \%$. The incidence of stunting in rural India is $48.3 \%$. Malnutrition, anaemia, poor socioeconomic status, poor health of mothers and cultural differences add up to the persistence of malnutrition in our country. Cognitive development and growth also gets affected when there are comorbid conditions like anaemia, worm infestation and respiratory infections.

This study is undertaken to find out the present status of undernutrition among a particular rural school in Irungalur village in the age group of 5-10 years, and the comorbid conditions which are present in these children. Marasmus and Kwashiorkor are only a tip of an iceberg indicating severe malnutrition. Most of the time in a community the grade I and grade II malnutrition is often overlooked on the presumption that these children will improve by nutritional advice alone. But the fact is these children stay in the same grade in spite of nutritional advice since the environment, socioeconomic status continues to be the same throughout the period of childhood. So, correction of undernutrition is not easy unless constant effort in monitoring their growth parameters, their diet charts, their family background, financial status of their parents, parental quarrelling, illnesses of their parents, alcoholism among males will help a long way in helping these school children to attain normal growth and development. The study also gives an insight into how far the mid-day meal scheme helps in balancing their nutritional status as it is presumed that it fills up the daily nutritional deficit.

Cultural practices greatly influence the prevalence of malnutrition among school children. School children don't like stereotyped food. But it is unavoidable among poor socioeconomic status. Added to these food fads, customs, traditions, beliefs, cooking practices, child rearing practices, attitudes and superstition, illiteracy among parents, also contribute to worsening of malnutrition. Lack of food is not the only problem. Often there is starvation in the midst of plenty. The truth is that in addition to infants and toddlers it also affects the school going children who are often overlooked.

The various practices including frequent hand washing, bathing, personal care, potable water, using toilets help a long way in preventing malnutrition. Various cooking practices like draining away water at the end of cooking, prolonged boiling in open pans, peeling vegetables before cooking tend to reduce the nutritional value of foods. Social factors including female sex, large family size, lack of spacing, overcrowding and unemployment also influence the quality of life. Tamilnadu health indices are much better when compared to national figures due to better coverage of immunisation, institutional deliveries, health care provider system and literacy rate. Malnutrition still affects $20.1 \%$ of rural children below 12 years due to the abovementioned factors which are prevalent in every society.

\section{MATERIALS AND METHODS}

\section{Type of Study}

A cross-sectional descriptive study done by measuring height, weight, general and systemic examination of children aged 5-10 years in a Government aided primary school of
Irungalur village near Chennai Medical College Hospital and Research Centre.

\section{Methodology}

Principal, Parents and Teachers were pre-informed about the visit to the school to take up the above study of nutritional assessment. All children studying between $1^{\text {st }}$ and $5^{\text {th }}$ standard were screened by measuring their weight, height, ascertaining the history of any illness and conducting the clinical examination from head to toe to find out common illnesses. Parents were called to give history in relevant cases if necessary. Weight and height were measured according to WHO protocols using Electronic weighing machine and stadiometer respectively by trained junior doctors.(3-6)

Sample size was not calculated because this study included all students studying in the school (selected), so sampling technique adopted was universal sampling. Total population of the village was 5502 and this is the only school catering to poor socioeconomic children. Study period was in the month of February 2017.

\section{Inclusion Criteria}

All children who attended the study on the particular day.

\section{Exclusion Criteria}

6 children who were absent on the day of study were excluded.

\section{RESULTS}

The children examined belong to age group of 5-10 years studying in Government aided primary school, Irungalur. 134 children were examined out of which $83(61.9 \%)$ were male and 51 (38.05\%) were female. Weight of the children was classified according to IAP and height for age was according to Waterlow classification.

Waterlow Classification Based on Height for Age (Reference Range)

\begin{tabular}{|c|c|}
\hline Classification & $\begin{array}{c}\text { Height for Age } \\
\text { (Percentage of Expected) }\end{array}$ \\
\hline Normal & $>95 \%$ \\
\hline First degree stunting & $90-95 \%$ \\
\hline Second degree stunting & $85-89 \%$ \\
\hline Third degree stunting & $<85 \%$ \\
\hline
\end{tabular}

\section{Waterlow Classification for Height for Age}

\begin{tabular}{|c|c|c|}
\hline Height for Age & Total No. of Cases & Percentage \\
\hline N $>95 \%$ & 101 & $75.37 \%$ \\
\hline Grade I 90-95\% & 25 & $18.65 \%$ \\
\hline Grade II $85-89 \%$ & 7 & $5.22 \%$ \\
\hline Grade III <85\% & 1 & $0.74 \%$ \\
\hline
\end{tabular}

\section{Interpretation}

75.37 percent were normal. 18.65 percent were grade I ( 25 children); 5.22 percent were grade II (7 children); 0.74 percent in grade III (1 child). 24.61 percent were underweight among the overall 134 children. 


\section{Grading of Stunting According to Sex}

\begin{tabular}{|c|c|c|c|}
\hline Height & Male (83) & Female (51) & Total \\
\hline Normal & $65(78.31 \%)$ & $36(70.58 \%)$ & 101 \\
\hline Grade I & $13(15.66 \%)$ & $12(23.52 \%)$ & 25 \\
\hline Grade Ii & $4(4.81 \%)$ & $3(5.88 \%)$ & 7 \\
\hline Grade III & $1(1.20 \%)$ & 0 & 1 \\
\hline Total & $\mathbf{8 3}$ & $\mathbf{5 1}$ & $\mathbf{1 3 4}$ \\
\hline
\end{tabular}

\section{Interpretation}

78.31 percent (65 children) were normal in males whereas 70.58 percent ( 36 children) were normal in females. 15.66 percent (13 children) were grade I in males whereas 23.52 percentage (12 children) were grade I in females; 4.81 percentage ( 4 children) were grade II in males whereas 5.88 percentage (3 children) were grade III in females; 1.20 percent ( 1 child) in grade III whereas no female child was in grade III. 21.67 percent (18 children) were short statured among male children whereas 29.4 percent (15 children) were short statured among female children.

\section{IAP Classification for Weight for Age (Reference Range)}

\begin{tabular}{|c|c|}
\hline Nutritional Status & $\begin{array}{c}\text { Weight for Age Percentage of } \\
\mathbf{5 0}^{\text {th }} \text { Percentile of Harvard } \\
\text { Standard }\end{array}$ \\
\hline Normal & $>80 \%$ \\
\hline Grade I PEM & $71-80 \%$ \\
\hline Grade II PEM & $61-70 \%$ \\
\hline Grade III PEM & $51-60 \%$ \\
\hline Grade IV PEM & $<50 \%$ \\
\hline
\end{tabular}

\section{IAP Classification for Weight for Age}

\begin{tabular}{|c|c|c|}
\hline Weight for Age & Total No. of Cases & Percentage \\
\hline N $>80 \%$ & 47 & $37.30 \%$ \\
\hline Grade I $71-80 \%$ & 54 & $40.29 \%$ \\
\hline Grade II $61-70 \%$ & 27 & $20.14 \%$ \\
\hline Grade III $51-60 \%$ & 6 & $4.47 \%$ \\
\hline Grade IV $<50 \%$ & 0 & 0 \\
\hline
\end{tabular}

\section{Interpretation}

37.30 percent were of normal weight. 40.29 percent (54 children) were grade I; 20.14 percent (27 children) were grade II; 4.47 percent ( 6 children) were grade III; $64.9 \%$ were underweight among the overall 134 children.

\section{Grading of Malnutrition According To Sex}

\begin{tabular}{|c|c|c|c|}
\hline Weight & Male (83) & Female (51) & Total \\
\hline Normal & $31(37.34 \%)$ & $16(31.37 \%)$ & 47 \\
\hline Grade I & $35(42.16 \%)$ & $19(37.25 \%)$ & 54 \\
\hline Grade II & $13(15.66 \%)$ & $14(27.45 \%)$ & 27 \\
\hline Grade III & $4(4.81 \%)$ & $2(3.92 \%)$ & 6 \\
\hline Total & $\mathbf{8 3}$ & $\mathbf{5 1}$ & $\mathbf{1 3 4}$ \\
\hline
\end{tabular}

\section{Interpretation}

37.34 percent ( 31 children) were normal in male children whereas 31.37 percent (16 children) were normal among female children. 42.16 percent (35 children) were grade I among male children whereas 37.25 percent (19 children) were grade I among female children; 15.66 percent (13 children) were grade II among male children whereas 27.45 percent (14 children) were grade II among female children; 4.81 percent ( 4 children) were grade III among male children whereas 3.92 percent ( 2 children) were grade III among female children. 62.63 percent (52 children) were underweight among male children and 68.62 percent (35 children) were underweight among female children among the overall 134 children.

\section{Morbidity Chart}

\begin{tabular}{|c|c|c|}
\hline Diseases & No. of Cases & Percentile \\
\hline URI & 32 & $23.79 \%$ \\
\hline Dental Caries & 18 & $13.43 \%$ \\
\hline Nutritional deficiency & & \\
\hline Anaemia & 30 & $22.38 \%$ \\
\hline Vit. A def. & 1 & $0.74 \%$ \\
\hline B complex def. & 1 & $0.74 \%$ \\
\hline Learning Disability & 4 & $2.9 \%$ \\
\hline Impetigo & 3 & $2.29 \%$ \\
\hline
\end{tabular}

\section{DISCUSSION}

Rural India has high incidence of underweight and stunted children as compared to urban India. In India, total percentage of stunted was $48.3 \%$, underweight was $20.1 \%$ respectively.

On analysing the height for age data, $75.37 \%$ (101) of the children were normal, $18.65 \%$ (25) were on $1^{\text {st }}$ degree stunting, $5.22 \%$ (7) were on $2^{\text {nd }}$ degree stunting \& $0.74 \%$ (1) were on $3^{\text {rd }}$ degree stunting. On analysing the height for age of the children according to sex, $78.31 \%$ (65) of total children were $>95 \%$ of expected height when compared to female $70.58 \%$ (36), $15.66 \%$ (13) were of grade I when compared to female $23.52 \%$ (12). In grade II stunting, $4.81 \%$ (4) were male and $5.58 \%$ (3) were female. $1.20 \%$ (1) classified as grade III stunting.

On analysing their weight for age, $37.3 \%$ (47) of children were $>80 \%$ of their expected weight \& $40.29 \%$ (54) of children belong to $1^{\text {st }}$ degree malnutrition, $20.14 \%$ (27) belong to grade II malnutrition, $4.47 \%$ (6) of children belong to grade III malnutrition. Classifying their nutritional status according to sex $37.34 \%$ (31) of total male children were $>80 \%$ of expected weight whereas in females $31.37 \%$ (16) were $>80 \%$ of expected weight. In grade I malnutrition, $42.16 \%$ (35) were male \& $37.25 \%$ (19) were female. $15.66 \%$ (13) were grade II in male when compared to $27.45 \%$ (14) female in grade II. Males were $4.81 \%$ (4) \& females were $3.92 \%$ (2) in grade III malnutrition. Surprisingly, there were no children in grade IV malnutrition in both sexes. $(4,7)$

On analysing their common disease pattern among the school children clinically, $23.79 \%$ (32) had URI, $22.38 \%$ (30) had Anaemia, 13.43\% (18) had dental Caries, and Learning Disability was noted in $2.9 \%$ (4). Other diseases constitute $<2 \%$ of children which include Vitamin A deficiency, B complex deficiency \& Impetigo. $(8,9)$

Among the various interventional programs, single-point interventions like nutritional supplementation and primary health care have failed to achieve the desired outcome. The factors that influence the intellectual development are namely genetics, nutrition and environment. Even then the contribution of each of these factors is difficult to evaluate individually. The effect of malnutrition in reducing the intellectual achievement is very difficult to separate from other associated retarding social factors and environment. 
There are some suggestions; stimulation along with nutritional supplementation may be a good choice. Hence, more effort is needed to develop composite intervention packages including several inputs. Irrespective of the precise mechanism, it has been established that growth, development and intelligence of malnourished and socially deprived children are at risk. Multideprivation including malnutrition has thus been identified as the most important constraint in the total development of children. Hence, multidisciplinary mode of intervention including primary healthcare, proper care during illnesses, nutritional supplementation, developmental stimulation, psychosocial support, environmental health and socioeconomic advancement. The package has to be integrated with the existing child welfare programs.

\section{Limitations}

Present study was conducted at one rural primary school in Trichy and hence the findings cannot be generalised. Though the health profile was stratified by age \& sex compiled, it was not possible to classify according to socioeconomic status.

\section{Strength}

However, a cross-sectional study on nutritional status of a typical rural school with children from very poor socioeconomic status gives an idea of implementing, improving \& modifying nutritional programs including noon meal scheme, for the policy makers, health professionals, teachers as well as parents.

\section{CONCLUSION}

On analysing the height, weight \& pattern of illness of the above 134 children, it is found that malnutrition is alarming among rural children of Tamilnadu. More than $75.37 \%$ were of normal height and $24.61 \%$ of them were short statured. Analysing their weights, $37 \%$ were $>80 \%$ of expected weight, $64.90 \%$ were underweight. No children were in grade IV malnutrition. URI and Anaemia were the major illnesses detected in above school children. Constant growth monitoring, deworming \& nutritional diet supplementation including iron will go a long way in preventing malnutrition as well as in addressing the minor ailments.(10,11) Addressing the cultural practices like food fads, increasing the per capita income by creating job opportunities, family planning, maternal health and addressing the individual nutritional need of these children by parental counselling, and finding ways to address the individual problem of these school going children will be the long term solutions.

\section{REFERENCES}

[1] Hashim NMZ, Sizali MS. Wireless patient monitoring system. International Journal of Science and Research 2013;2(8):250-5.

[2] Fazili A, Mir AA, Pandit BM, et al. Nutritional status of school age children (5-14 years) in a rural health block of North India (Kashmir) using WHO Z-Score system. Online Journal of Health and Allied Sciences 2012;11(2).

[3] Srivastava A, Mahmood SE, Srivastava PM, et al. Nutritional status of school-age children-a scenario of urban slums in India. Archives of Public Health 2012;70(1):8.

[4] Joice S, Velavan A, Natesan M, et al. Assessment of nutritional status and morbidity pattern among school children of rural Puducherry. Academic Medical Journal of India 2013;1(1):32-5.

[5] Ahmad HR, Kesari KK, Prasad R, et al. Assessment of nutrition status of 7-10 years school going children of Allahabad district: a review. Middle East journal of scientific research 2008;3(3):109-15.

[6] Khadilkar V, Yadav S, Agrawal KK, et al. Revised IAP growth charts for height, weight and body mass index for 5-to 18-year-old Indian children. Indian pediatrics 2015;52(1):47-55.

[7] Kamath R, Jakkula RP, Kumar S. Nutritional status assessment of school children in Bellary district, Karnataka. Journal of Dr. NTR University of Health Sciences 2015;4(1):13-6.

[8] Ananthakrishnan S, Pani SP, Nalini P. A comprehensive study of morbidity in school age children. Indian pediatrics 2001;38(9):1009-17.

[9] Muthayya S, Thankachan P, Zimmermann MB, et al. Low anemia prevalence in school-aged children in Bangalore, South India: possible effect of school health initiatives. European journal of clinical nutrition 2007;61(7):865-9.

[10] Arnold F, Parasuraman S, Arokiasamy P, et al. Nutrition in India. National family health survey (NFHS-3), India 2005;6:59.

[11] Ruel MT, Alderman H. Nutrition-sensitive interventions and programmes: how can they help to accelerate progress in improving maternal and child nutrition? The Lancet 2013;382(9891):536-51. 